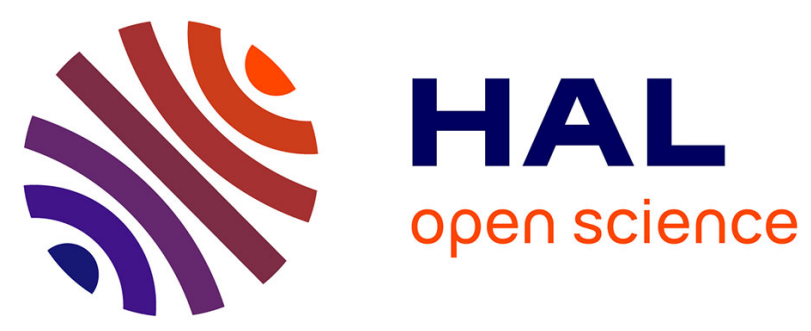

\title{
From the experimental characterization of the hygrothermal properties of straw-clay mixtures to the numerical assessment of their buffering potential
}

Matthieu Labat, Camille Magniont, Nicolaas Oudhof, Jean-Emmanuel Aubert

\section{- To cite this version:}

Matthieu Labat, Camille Magniont, Nicolaas Oudhof, Jean-Emmanuel Aubert. From the experimental characterization of the hygrothermal properties of straw-clay mixtures to the numerical assessment of their buffering potential. Building and Environment, 2016, 97, pp.69 - 81. 10.1016/j.buildenv.2015.12.004 . hal-01785406

\author{
HAL Id: hal-01785406 \\ https://hal.science/hal-01785406
}

Submitted on 4 May 2018

HAL is a multi-disciplinary open access archive for the deposit and dissemination of scientific research documents, whether they are published or not. The documents may come from teaching and research institutions in France or abroad, or from public or private research centers.
L'archive ouverte pluridisciplinaire HAL, est destinée au dépôt et à la diffusion de documents scientifiques de niveau recherche, publiés ou non, émanant des établissements d'enseignement et de recherche français ou étrangers, des laboratoires publics ou privés. 


\title{
From the experimental characterization of the hygrothermal properties of straw-clay mixtures to the numerical assessment of their buffering potential
}




\section{ABSTRACT}

The development of innovative materials has to respond to both environmental and energy concerns. Bio-based materials are relevant because they are made from renewable raw materials and are carbon neutral. Similarly, unprocessed earth has a very low embodied energy. In this paper, the basic hygrothermal properties of straw-clay samples provided by two French companies were determined. Mixes with densities lower than $450 \mathrm{~kg} \cdot \mathrm{m}^{-3}$ would be suitable for use as self-insulating material in current construction. In addition, the material showed a high sorption capacity and very high water vapour permeability. The measurements were then implemented in a numerical model in order to simulate the hygric response of a small room. The straw-clay mixture was found to have a moisture buffering effect of the same magnitude as walls made of hemp concrete and largely higher than conventional walls. The influence of various indoor finishing materials was investigated through additional simulations.

KEYWORDS

Straw-clay, hygrothermal properties, moisture buffering potential, biobased materials 


\section{Introduction}

Within the context of sustainable development, the reduction of environmental impacts has become a priority in many sectors. In France, the building sector is responsible for $43 \%$ of energy consumption and $25 \%$ of greenhouse gas emissions. It also uses large quantities of non-renewable raw materials and produces large amounts of waste [1]. These impacts are generated during the production of construction materials and also by the use of the building. In consequence, the development of innovative materials has to respect environmental and social concerns. From the energy point of view, the building's overall energy consumption has to be minimized first, which brings the need for thermally efficient materials to the fore. Second, a low environmental footprint is required and, finally, achieving comfortable, healthy indoor conditions without using energy consuming systems (such as HVACs) is an on-going topic.

\subsection{On the use of earth mixed with bio-based materials in construction}

Concerning the environmental aspects, bio-based materials are relevant in the field of building construction: they are made from renewable raw materials (mainly local by-products of agricultural activities) and are carbon neutral. Similarly, unprocessed earth is an abundant local resource with very low embodied energy, which is cheap and easy to work. These advantages explain why earth construction is still the most widespread building technique in the world. Today, a third of the world's population still live in earth housing, half of them in developing countries [2]. During the last 15 years, there has been a resurgence of interest in earth construction, resulting in the development of scientific research on this topic as illustrated by the publication of two recent reviews [3,4]. The research works reviewed in these papers mainly focus on the effect of stabilization (with hydraulic binder or plant fibres) on the mechanical performance, shrinkage and durability of soil blocks or rammed earth.

However, earth and bio-based materials present other advantages that are worth studying, namely their hygrothermal properties [5,6], which describe how the material participates in heat and water vapour transfer. Consequently, studying these properties is a first step in evaluating the impact of the material not only on energy consumption for heating, but also on indoor comfort, which depends strongly on temperature and relative humidity. This influence, often referred to as the moisture buffering capacity, will be presented further in section 1.2.

The positive impact of earth on comfort is often mentioned, yet no extensive study is available on this specific topic. In fact, this is not very surprising as it has also been observed that the hygrothermal properties of earth materials were poorly described in the literature until recently. McGregor et al. [7] investigated the moisture buffering effect of unfired clay masonry, demonstrating the strong influence of clay plasters and blocks on indoor humidity. They also observed the marked influence of the clay mineralogy on hygrothermal properties. The hygrothermal characteristics of earth bricks have been measured and their ability to quickly absorb a significant amount of water vapour highlighted [8]. Similar measurements have been carried out to assess the influence of the production process (namely extrusion) on the hygrothermal properties of earth bricks [9]. Strong anisotropy was observed for both thermal and hygric properties due to the orientation of the clay platelets. In numerical simulations achieved to compare the influence of several types of indoor finishing, the advantages of using a clay- 
based coating rather than gypsum or acrylic stucco plaster have been demonstrated, regarding comfort and energy consumption [10]. Allinson and Hall [11] studied the hygrothermal performance of rammed earth using both experimental and numerical tools. This study concluded on the good moisture capacity of stabilized rammed earth (SRE).

Compared to earth, bio-based materials have lower thermal conductivity and can therefore be used as a thermally insulating material to reduce energy consumption. A glance at the respective advantages of bio-based aggregates and earth shows that they are complementary: earth can be used to maintain a comfortable indoor environment while highly porous bio-based materials can help to achieve efficient thermal insulation by lightening the composites. And, of course, both are highly compatible with the desire to preserve the environment as mentioned above.

The straw-clay construction technique consists of mixing straw with diluted earth found on site. After one night of draining, straw-clay is cast on site and packed by hand between two temporary formwork panels around a wood frame. Formwork is removed the same day. Different dry densities can be reached by modifying the proportions of clay and straw, but common densities range from 400 to $500 \mathrm{~kg} \cdot \mathrm{m}^{-3}$. The present study results from a project initiated by two construction companies, Ecoterre and Inventerre, located in the south of France and working with the straw-clay technique. According to the builders and to the people living in buildings where straw-clay was used as infill insulating material, a comfortable indoor environment was achieved with no significant increase in energy consumption. However, very few studies could be found in the scientific literature to back up this statement. This is a direct consequence of the lack of data for such mixtures, which results in their poor integration in current thermal regulations and numerical studies. So the first objective of this work was to fill that gap.

To the best of our knowledge, only one scientific study [12] on straw-clay exists in the literature. It used samples with a measured density of $440 \mathrm{~kg} \cdot \mathrm{m}^{-3}$ and a rather high thermal conductivity was obtained $\left(0.18 \mathrm{~W} \cdot \mathrm{m}^{-1} \cdot \mathrm{K}^{-1}\right)$. However, no hygroscopic properties were measured. Looking at other types of bioaggregates, few papers can be found where earth is used as a matrix; they include wood [13-17] corn cob [18], straw [17], oat fibres [19], Hibiscus cannabinus fibres [20,21], coconut coir [22], millet [23], sawdust [24] or phytomass [25]. In these studies, it should be noted that the biomass content was very low in comparison with straw-clay, and this resulted in densities higher than $1000 \mathrm{~kg} \cdot \mathrm{m}^{-3}$ in most cases. As mentioned in [26], there is a relationship between density and thermal conductivity: thermal conductivity increases linearly with density. Therefore, thermal conductivities higher than $0.5 \mathrm{~W} \cdot \mathrm{m}^{-1} \cdot \mathrm{K}^{-1}$ were obtained, making the material unsuitable for thermal insulation purposes. A noteworthy exception can be found in $[13,14]$, where lighter mixes were obtained by incorporating wood aggregate in a higher content. Measured densities were 370 and $621 \mathrm{~kg} \cdot \mathrm{m}^{-3}$ respectively, and thermal conductivities were 0.08 and $0.13 \mathrm{~W} \cdot \mathrm{m}^{-1} \cdot \mathrm{K}^{-1}$. The equilibrium moisture content (EMC) of earth plaster incorporating wheat straw, barley straw and wood shavings has also been studied [17]. EMC was found to increase with the plant matter content and to depend on the nature of the plant. Similar results were obtained by Maddison et al. [25], who showed that both the amount of water absorbed and the kinetics of absorption were increased by the presence of phytomass. Concerning water vapour permeability, two references were found for earth plaster with bio-based addition [12,19]. A water vapour resistance factor, $\mu$, of 8 was obtained in the wet cup test. This result is very low in comparison with conventional cement-based plaster and suggests a high potential buffering effect. 
To sum up, the reports on hygrothermal properties of earth mixed with bio-based materials are rather scattered in the literature, especially for straw-clay mixtures. In this paper, we propose a contribution to this field in the form of a hygrothermal measurement campaign on samples provided by two companies specializing in the construction of straw-clay buildings. We compare the results obtained on straw-clay samples with those for earth materials including plant matter and also with bio-based and conventional self-insulating building materials (i.e. hemp concrete, wood concrete and aerated autoclaved concrete) with similar physical properties. These preliminary experimental results will help to highlight the potential use of straw clay mixtures in building. Finally, it should be mentioned that the properties will depend on the design of the straw-clay mixture, the mineralogical properties of the soil [7] and the nature of the straw. However, this falls outside the framework of this paper and will not be discussed.

\subsection{Buffering potential of hygroscopic materials}

Among the possible advantages of this material, its ability to maintain comfortable indoor environments may need to be described more precisely. It refers to the buffering capacity of hygroscopic materials, which is a well-known effect already presented by numerous authors. It represents the ability of the materials (interior objects, finishing, etc.) to adsorb and release moisture when exposed to a variation of relative humidity. This results in a smoothing of the indoor relative humidity variations. In the literature, this effect is estimated using various experimental protocols and numerical approaches.

The MBV (Moisture Buffering Value) test [27] is a widespread experimental protocol, in which small samples are subjected to relative humidity cycles. A comparison with a similar protocol developed in Japan is proposed in [28]. One of the advantages of the MBV test is that it is simple and easy to perform. Nevertheless, it should be mentioned that a recent study highlighted the strong sensitivity of the results to the air velocity in the climatic chamber [29].

The results from the MBV test are not very representative of the buffering effect at room scale and it has been acknowledged in several studies [30-33] that the hygric response of a room depends both on the moisture buffering capacity of indoor finishing materials and on the air change rate. However, the latter is not taken into account in MBV tests. Therefore, other indexes can be found in the literature to represent the buffering potential of the construction materials.

- The Moisture Adsorption / Desorption Effect (MBEa and MBEd) indexes were defined in [32], based on the evolution of temperature and relative humidity of indoor air ;

- Another similar index, named the Effective Dampened Relative Humidity (EDRH), was presented in [34];

- The Maximum Accumulated Buffering Value (MAMBV) was proposed in [31] and relies on a moisture balance achieved at the room scale.

- The Hygric Inertia of a Room (HIR) was defined in [35]. It is combines the results of different MBV tests to characterize the hygric inertia of a complete enclosure.

It emerges that there is no consensus in the methodology that should be used to calculate the moisture buffering potential of the construction materials. Also, samples are subjected to cyclic steps of indoor 
relative humidity with the $\mathrm{MBV}$ test, whereas indoor humidity variations are not so quick and homogeneous in real rooms [36,37]. Moreover, the samples have to be thicker than the moisture penetration depth, which can be defined as the depth where the amplitude of moisture content variations is only $1 \%$ of the variation on the material surface. This value can be predicted analytically on the basis of knowledge of the material properties and by assuming a semi-infinite isothermal material exposed to a sinusoidal excitation. In the case of vapour permeable materials, however, the moisture penetration depth may be significantly greater than the usual thicknesses: for example, the moisture penetration depth can reach $10 \mathrm{~cm}$ for gypsum boards, while indoor sidings are generally $13 \mathrm{~mm}$ thick. It was also observed for hemp lime or flax lime concretes that the theoretical penetration depth was significantly smaller than the experimentally observed value [38].

A finishing cover is generally applied to indoor sidings in real buildings and this has been shown [39] to significantly decrease the vapour permeability of the material, resulting in a decrease of the buffering effect. For multi-layered walls, it has also been observed [40] that moisture transfers are influenced by the wall assembly. For example, vapour barriers are often used in lightweight buildings, which strongly impact the moisture balance at room scale. Therefore, the hygric response of a room should be determined by considering the whole wall assembly, and not only the indoor siding, unless a vapour barrier is considered as in [31]. Finally, it should be mentioned that the outdoor conditions also have an influence. First, they affect the indoor moisture balance by air renewal. Second, direct solar irradiance influences moisture transfers in the walls (the so-called sun-driven moisture transfer [41,42]). However, the latter phenomenon is not systematically taken into account as it requires an accurate definition of the outdoor conditions, thus restricting the study to a specific climate.

This illustrates some of the limits of the MBV test when it comes to discussing the impact on indoor comfort. Even though the test is relevant to compare different materials, we propose to use another approach to estimate the buffering potential of straw-clay mixtures, namely a numerical model. However, numerical models are not free from biases and progress is needed to assess their reliability. For example, it is well known that the sorption isotherm presents a hysteresis cycle [43-46], which is likely to impact vapour transfer. However, it is not straightforward to model and many authors are still using the sorption isotherm only $[39,47,48]$. In the present work, as the numerical results rely on preliminary measurements, we propose to use a simplified approach that neglects the hysteresis. The

overall objective is to compute an index that would represent the global influence of the wall assembly on indoor humidity rather than to propose an in-depth description of the physical phenomena. Similar attempts can be found in the literature; one or more could be used to extend the comparison between straw-clay material and others. In this paper, we follow the methodology presented in [28] to analyse the hygric response of a small room for various wall configurations under simplified boundary conditions. It is acknowledged that reality is far more complex but this numerical approach could constitute an interesting alternative to MBV tests.

\subsection{Objectives of this paper}

To summarize, this paper has two main objectives: first, it presents the measurements of the hygrothermal properties of straw-clay samples provided by two French manufacturers (Ecoterre and 
Inventerre). Thermal conductivity, vapour sorption isotherms, and water vapour permeability measurements are presented in section 2. Second, the buffering potential of such a mixture is assessed by using a numerical approach as an alternative to the MBV test. To this end, a coupled heat and mass transfer model is used to determine the hygric response of a small room. The analysis focuses on the ability of the material to damp the amplitude of indoor relative humidity variations. This will allow the buffering effect of the straw clay mixture to be further characterized, and provide a comparison with other typical wall assemblies. The novelty of this work is to combine both an experimental and a numerical approach to investigate the hygrothermal properties of a bio-based building material with earth matrix.

\section{Experimental characterization of straw clay mixtures}

\subsection{Experimental procedures and apparatus}

\subsubsection{Materials and sampling}

Straw-clay samples were provided by the builders. Earth extracted on site was mixed with a large quantity of water in a classic concrete mixer. Then, this fresh mix was sieved and poured into a large container. Straw was soaked in the diluted clay and drained in piles. Straw-clay mixture was then cast and packed by hand into the mould. Although this production method is very convenient, the samples revealed apparent heterogeneities (Fig. 1).
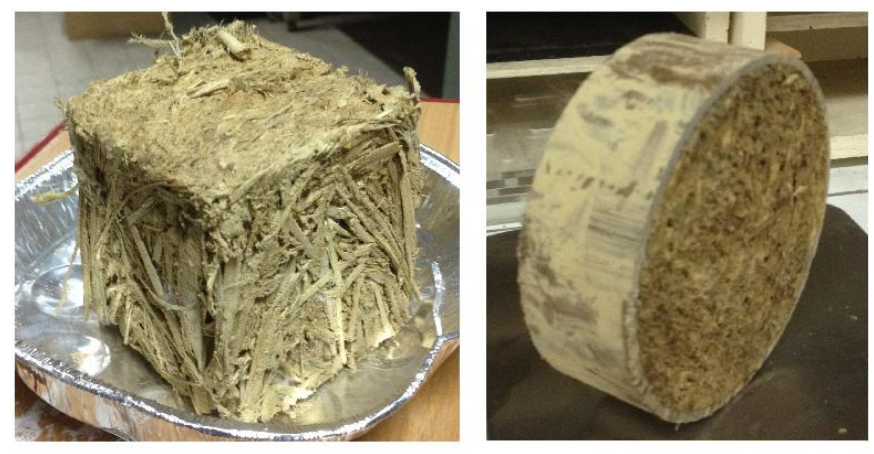

Fig. 1: Straw clay samples with different geometries

A density measurement campaign was carried out on 25 large samples $\left(7^{*} 7^{*} 7 \mathrm{~cm}^{3}\right)$, taken at mid height in the mould in order to obtain a representative volume and to avoid edge effects. The results revealed an average density of $399 \mathrm{~kg} \cdot \mathrm{m}^{-3}$ and a relative dispersion close to $7 \%$. This low scatter showed the good reproducibility of fabrication and gave confidence in the sampling processes.

\subsubsection{Thermal conductivity}

Tests were performed in accordance with the ISO 12664 standard [49], with a hot plate apparatus ( $\lambda$ Meter EP 500, Lambda-Messtechnik $\mathrm{GmbH}$, Dresden). The accuracy of the thermal conductivity measurement is close to $5 \%$. Measurements were made at $25^{\circ} \mathrm{C}$ with $10 \mathrm{~K}$ temperature difference between the two plates. The steady state was assumed to have been reached when the change in 
conductivity was less than $1 \%$ in 60 minutes. Plane-parallel samples with $15^{*} 15 \mathrm{~cm}^{2}$ sections and $7 \mathrm{~cm}$ thickness were tested. The compaction process applied during the fabrication of a straw clay wall may induce a preferred orientation of straw elements and then an anisotropic behavior. Such results have been previously demonstrated on hemp concrete. In [50], thermal conductivity was measured according to parallel and perpendicular directions with the compaction direction. The ratio between these two values varied from 1.1 to 1.24. In the present study, as shown on Fig. 2, the compaction of the specimen and the sampling were realized in order to reproduce the orientation of straw in a real straw-clay wall.

Prior to testing, specimens were dried in an oven at $55^{\circ} \mathrm{C}$ until the change in mass of the sample was less than $0.1 \%$ between two weighing 24 hours apart. The results presented here are mean values of measurements taken on at least 3 different samples.

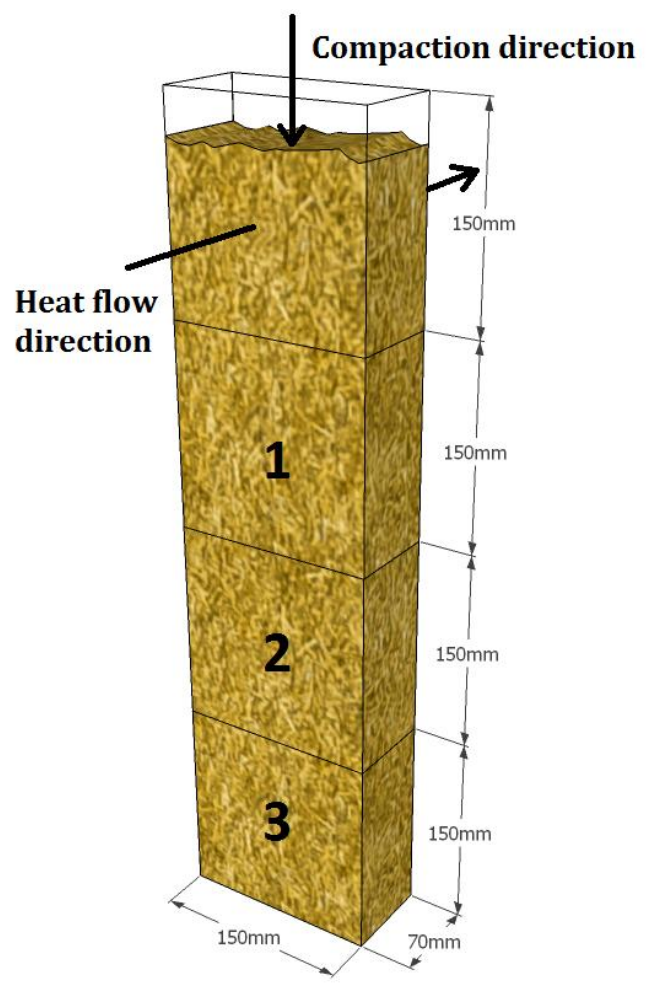

Fig. 2: Schematic representation of fabrication and sampling processes for conductivity measurement

\subsubsection{Water vapour sorption}

The moisture content was calculated using Eq. 1.

Eq. 1

$$
u_{i}=\frac{m_{i}-m_{0}}{m_{0}}
$$

Each mass was determined by averaging 3 successive measurements made on a balance accurate to $\pm 0.01 \mathrm{~g}$. Measurements were made on 25 large samples $\left(7^{*} 7^{*} 7 \mathrm{~cm}^{3}\right)$, taken at mid height in the mould.

It can be seen in Eq. 1 that the measurement accuracy depends on the estimation of the mass in the dry state. In the ISO 12570 standard [51], the definition of the dry state is not very clear: it is stated that the 
dry state is obtained if the mass variation of the sample remains lower than $0.1 \%$ over $24 \mathrm{~h}$, when the relative humidity is lower than $10 \%$. However, a significant mass variation is expected when $\psi$ increases from 0 to $10 \%$.

Here, samples were placed in an oven maintained at $55^{\circ} \mathrm{C}$ and the relative humidity was monitored by a KISTOCK KH 110 sensor. All the samples were weighed for 3 different levels of relative humidity $(5,7$ and $9 \%)$. A linear relationship was fitted for each sample: this allowed the mass in the dry state to be estimated (i.e., when the relative humidity was equal to 0 ). The values obtained ranged from $134.96 \mathrm{~g}$ to $184.26 \mathrm{~g}$, and the average value was $160 \mathrm{~g}$.

Sorption and desorption measurements were achieved according to the ISO 12571 standard [52]. Both a climatic chamber (System Weiss, WK3 2000/40) and saturated salt solutions were used to maintain a constant level of relative humidity. Saturated salt solutions were placed in airtight plastic boxes, which were placed in the climatic chamber so that the temperature was maintained at $23^{\circ} \mathrm{C}$ throughout the experiment. In some cases, the samples were placed directly in the climatic chamber.

All the samples were used to measure the sorption value at $9 \%$. A very low deviation was obtained $(0.02 \%)$. In order to reduce the duration of the measurement, the samples were separated in small groups, containing from 3 to 12 samples (see Table 1). This allowed all the measurements to be made within 3 months. Desorption measurements were performed with 12 samples only, those that were exposed to the highest relative humidity $(\psi=93 \%)$.

Each sample was weighed periodically until the difference between two consecutive measurements, $24 \mathrm{~h}$ apart, was less than about $0.1 \%$. The final value corresponded to the average moisture content of all the samples. The standard deviation increased with relative humidity to reach as much as $1.26 \%$ for $\psi=93 \%$.

Table 1 : Distribution of the samples for sorption and desorption measurements

\begin{tabular}{lllllll}
\hline$\Psi$ & $9 \%$ & $22 \%$ & $50 \%$ & $66 \%$ & $81 \%$ & $93 \%$ \\
\multirow{5}{*}{ Sorption } & $\mathrm{CC}$ & $\mathrm{SS}-\mathrm{CH}_{3} \mathrm{COOH}$ & $\mathrm{CC}$ & $\mathrm{SS}-\left(\mathrm{NaNO}_{2}\right)$ & $\mathrm{SS}-\left(\mathrm{NH}_{4}\right)_{2} \mathrm{SO}_{4}$ & $\mathrm{SS}-\mathrm{KNO}_{3}$ \\
& 25 samples & 4 samples & 8 samples & 4 samples & 4 samples & 12 samples \\
\multirow{5}{*}{ Desorption } & $\mathrm{SS}-\mathrm{KOH}$ & $\mathrm{SS}-\mathrm{CH}_{3} \mathrm{COOH}$ & & $\mathrm{CC}$ & $\mathrm{SS}-\left(\mathrm{NH}_{4}\right)_{2} \mathrm{SO}_{4}$ & $\mathrm{X}$ \\
& 3 samples & 3 samples & & 3 samples & 3 samples & \\
\hline
\end{tabular}

CC : Climatic Chamber SS : Salt Solution

\subsubsection{Water vapour permeability}

The vapour diffusion measurement was carried out according to the ISO 12572 standard [53]. Dry (9\%) and wet $(93 \%)$ cups were prepared by sealing cylindrical straw-clay samples with a mixture of paraffin (40\%) and beeswax (60\%) on PVC cups containing saturated salt solutions of $\mathrm{KOH}$ and $\mathrm{KNO}_{3}$ respectively (see Fig. 3). Three cylindrical samples (diameter: $118 \mathrm{~mm}$, height 26 to $28 \mathrm{~mm}$ ) were tested for each condition. The thickness of the air layer between the sample and the saturated salt solutions was lying between 17 and $19 \mathrm{~mm}$. The complete systems were placed in a climatic chamber (System Weiss, WK3 2000/40) kept at $23^{\circ} \mathrm{C}$ and $50 \% \mathrm{RH}$. The mass of samples was monitored through daily weighing. 


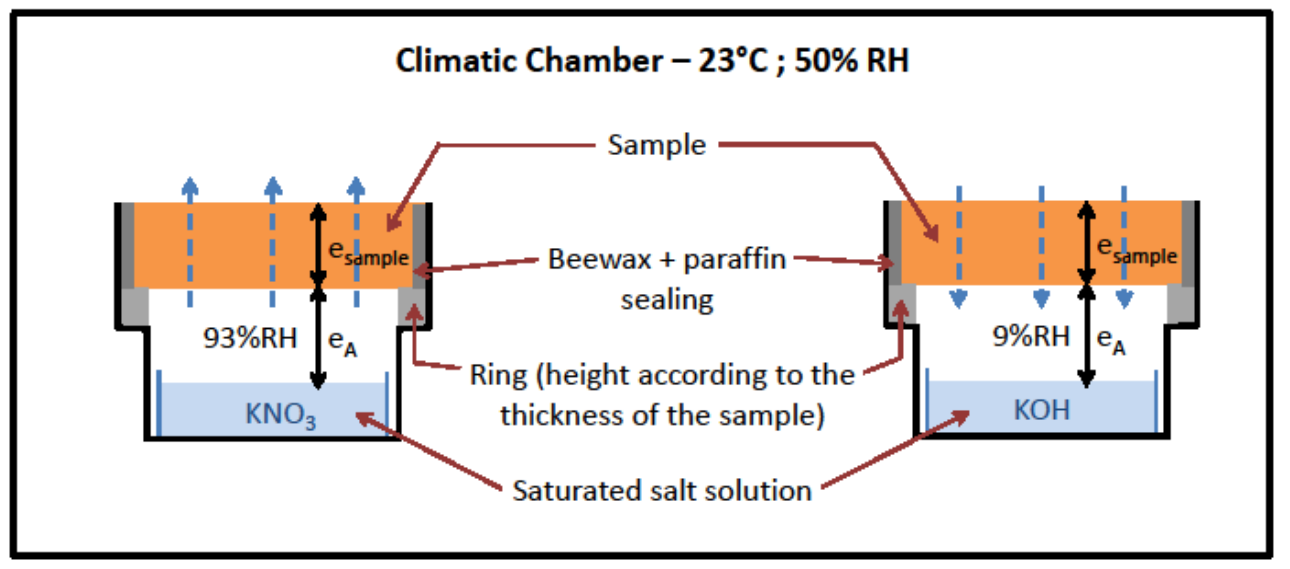

Fig. 3: Principle of the cup method for water vapour permeability measurement

This experiment allows determining the vapor flux through the specimen. In a similar manner to heat transfer, the vapor flux is defined as the ratio between the vapor resistance $R_{v}$ and the vapor pressure difference maintained by the salt solutions and the climatic chamber.

Eq. 2

$$
g_{V}=\frac{p_{V, S S}-p_{V, C C}}{R_{V}}
$$

The vapor resistance of the assembly is the sum of three resistances: the one of the sample itself $\left(\mathrm{R}_{\mathrm{V}, \text { Sample }}\right)$ and the ones of the air layers located between the sample and the salt solution $\left(\mathrm{R}_{\mathrm{V}, \mathrm{SS}}\right)$ and between the sample and the climatic chamber $\left(\mathrm{R}_{\mathrm{V}, \mathrm{CC}}\right)$.

Eq. 3

$$
R_{V}=R_{V, S S}+R_{V, \text { Sample }}+R_{V, C C}
$$

Because of the air velocity into the climatic chamber, the resistance of the air layer above the sample is significantly lower than the two others, so it can be neglected. The water vapor resistance of the air layer below the sample is calculated by estimating its thickness as follow:

Eq. 4

$$
\mathrm{R}_{\mathrm{V}, \mathrm{SS}}=\frac{\mathrm{e}_{\mathrm{A}}}{\pi_{\mathrm{A}}}
$$

Finally, the water vapor permeability of the material $(\pi)$ is given as:

Eq. 5

$$
\pi=\frac{\mathrm{e}_{\text {sample }}}{\mathrm{R}_{\mathrm{v}}-\frac{\mathrm{e}_{\mathrm{A}}}{\pi_{\mathrm{A}}}}
$$

The resistance of a material to water vapor diffusion is often expressed by the mean of two other indexes, which derive from the water vapor permeability: the water vapor resistance factor $(\mu)$ and the water vapor diffusion equivalent air layer thickness (Sd). 
Eq. 6

$$
\mu=\frac{\pi_{A}}{\pi}=\frac{S_{d}}{e}
$$

\subsection{Results}

\subsubsection{Thermal conductivity}

Five different mixtures of straw-clay were provided by the companies (Ecoterre and Inventerre). The straw to clay ratio was modified so as to obtain a dry material with variable density $(\rho)$. The mean values of thermal conductivity $(\lambda)$ obtained for each formulation are reported in Table 2.

Table 2: Average thermal conductivity values of the 5 straw-clay mixtures (standard deviation)

\begin{tabular}{|c|c|c|c|c|c|}
\hline Mixtures & 1 & 2 & 3 & 4 & 5 \\
\hline $\begin{array}{c}\rho \\
\left(\mathrm{kg} \cdot \mathrm{m}^{-3}\right)\end{array}$ & $\begin{array}{l}241 \\
(42)\end{array}$ & $\begin{array}{l}381 \\
(6)\end{array}$ & $\begin{array}{l}403 \\
(14)\end{array}$ & $\begin{array}{l}449 \\
(18)\end{array}$ & $\begin{array}{l}531 \\
(30)\end{array}$ \\
\hline $\begin{array}{c}\lambda \\
\left(\mathrm{W} \cdot \mathrm{m}^{-1} \cdot \mathrm{K}^{-1}\right)\end{array}$ & $\begin{array}{c}0.071 \\
(0.004)\end{array}$ & $\begin{array}{c}0.088 \\
(0.002)\end{array}$ & $\begin{array}{c}0.099 \\
(0.007)\end{array}$ & $\begin{array}{c}0.104 \\
(0.002)\end{array}$ & $\begin{array}{c}0.120 \\
(0.005)\end{array}$ \\
\hline
\end{tabular}

As expected, thermal conductivity increased with density. For $\rho$ ranging from 241 to $531 \mathrm{~kg} \cdot \mathrm{m}^{-3}, \lambda$ was between 0.071 and $0.120 \mathrm{~W} \cdot \mathrm{m}^{-1} \cdot \mathrm{K}^{-1}$. Note the quite low dispersion of the final dry densities in each group ( $<5 \%$ except for the lightest mixture). This reveals a good knowledge of the fabrication process by those involved and their ability to produce a material with repeatable density.

All the values of $\lambda$ measured during this campaign are plotted in Fig. 4, together with values of earthbased, bio-based and conventional building material conductivities found in the literature. References are $[6,50,54]$ for hemp concrete, [55] for AAC, [13-15] for wood clay, [11] for straw clay, and [16] for straw clay plaster.

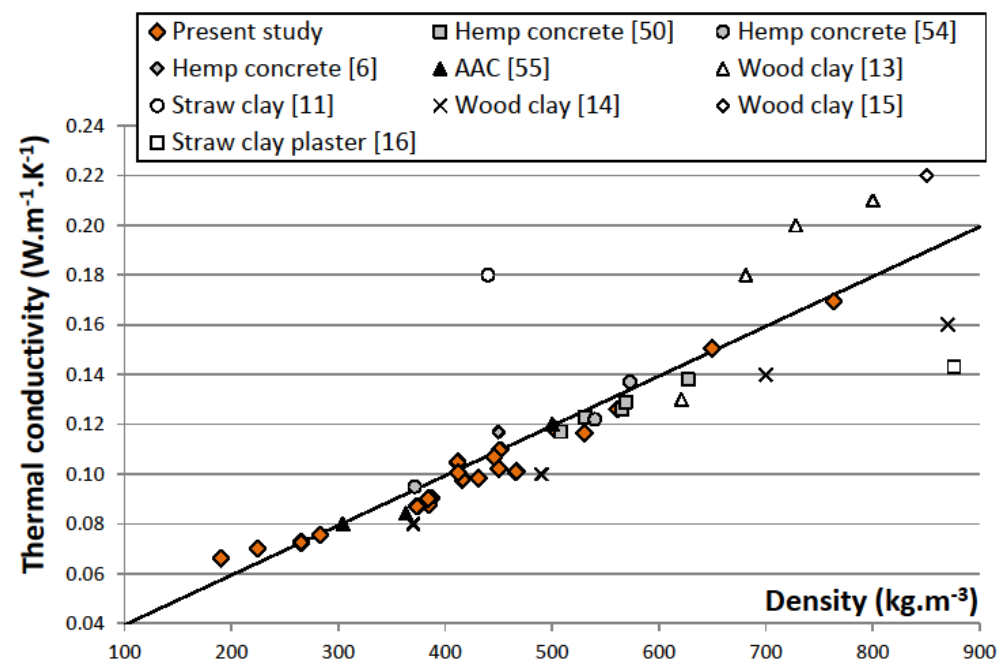

Fig. 4: Thermal conductivity versus dry density for straw-clay and other construction materials

As shown in Table 2, the dry thermal conductivities of straw-clay mixtures were comparable with those of hemp concretes or aerated autoclaved concrete (AAC) of equivalent density. These experimental 
results are in good agreement with the empirical relationship (see Eq. 7) established on hemp concretes in [26].

Eq. 7

$$
\lambda=0.0002 \cdot \rho+0.0194
$$

Thermal conductivity results obtained on other bio-based materials with earth matrices were more scattered (in particular, for other straw-clay mixtures and wood clay). The conductivity measured in [12] on straw clay looked particularly strongly overestimated. This could be related with the moisture content of earth-based samples, often not specified in these studies. Previous works highlighted the strong impact of water content on the thermal performances of clay materials $[7,23,24]$.

\subsubsection{Water vapour sorption}

In order to ease the comparison with other materials, several regression curves were tested. In [56], 3 theoretical models were used to represent the sorption isotherms for construction materials, but only the Kumaran model (see Eq. 8) and the Burch model (see Eq. 9) gave satisfactory results. Another model known as the GAB model (see Eq. 10) is also widely used nowadays according to [57] and is based on the moisture content.

Eq. 8

$$
u=\frac{\psi}{a \psi^{2}+b \psi+c}
$$

Eq. 9

$$
u=a \cdot\left(\frac{1}{1-\psi}-1\right)^{b}
$$

Eq. 10

$$
u=\frac{C_{G} \cdot k \cdot \psi}{(1-k \cdot \psi) \cdot\left(1-k \cdot \psi+C_{G} \cdot k \cdot \psi\right)} \cdot w_{m}
$$

The fitting coefficients were obtained by an inverse method (Generalized Reduced Gradient method) by minimizing the sum of the squared errors. Results were compared by computing the Pearson's correlation coefficient (see Eq. 11).

Eq. 11

$$
r_{x y}=\frac{\sum_{i}\left(x_{i}-\bar{x}\right) \cdot\left(y_{i}-\bar{y}\right)}{\sqrt{\sum_{i}\left(x_{i}-\bar{x}\right)^{2} \cdot \sum_{i}\left(y_{i}-\bar{y}\right)^{2}}}
$$

The computed coefficients were higher than 0.975 in all cases, meaning that the models were appropriate for the measurements. This can be seen in Fig. 5 . The best results were obtained with the GAB model, which was therefore selected to model the sorption isotherm. The fitted coefficients were $\mathrm{C}_{\mathrm{G}}=2.9772 .10^{1}, \mathrm{k}=9.7077 .10^{-1}$, and $\mathrm{w}_{\mathrm{m}}=1.1897 .10^{-2}\left(\mathrm{~kg}_{\mathrm{v}} \cdot \mathrm{kg}^{-1}\right)$. Finally, very low hysteresis was observed between sorption and desorption measurements. This resulted in similar fitted coefficients. For the sake of clarity, only the results for sorption are presented here. 


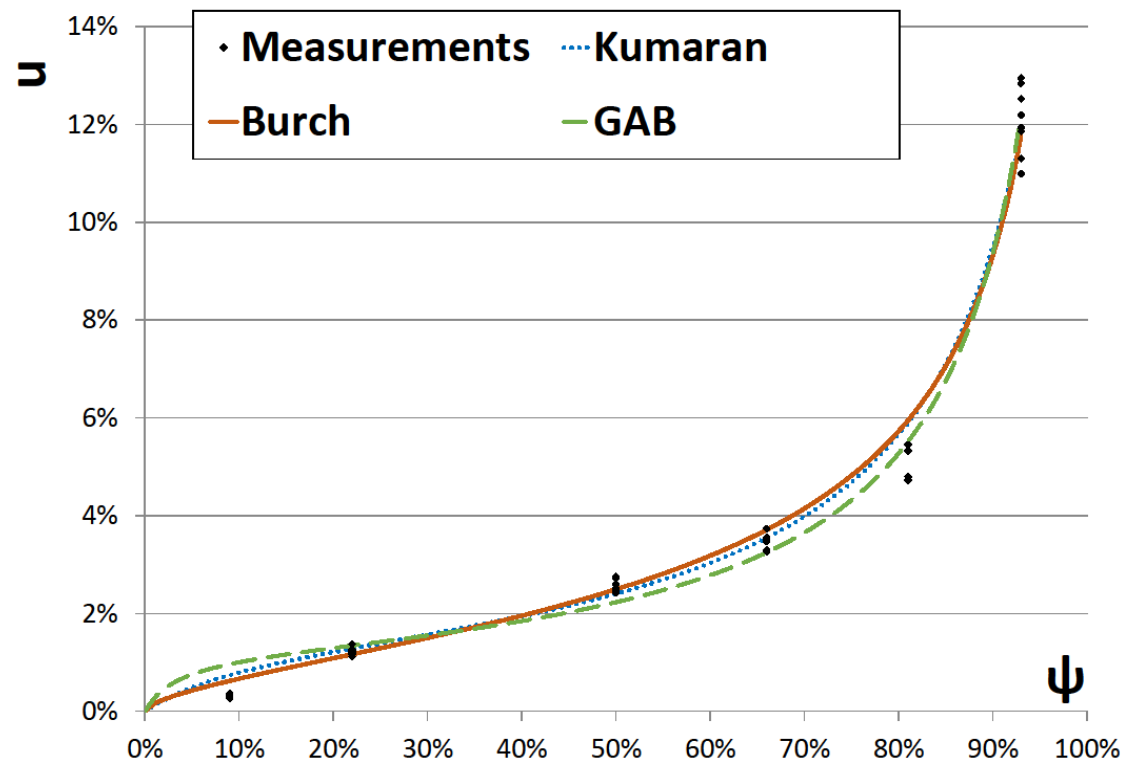

Fig. 5: Comparison of the 3 regression curves for sorption at $23^{\circ} \mathrm{C}$

\subsubsection{Water vapour permeability}

The results of water vapour permeability obtained with wet and dry cup methods are presented in Table 3. The measurements show that straw-clay is highly permeable to water vapour transfer. The spread of the experimental results looks acceptable in comparison with results presented in [58] for gypsum board, which is a very common building material.

Table 3: Average water vapour diffusion characteristics of straw-clay (standard deviation)

\begin{tabular}{ccccc}
\hline Method & $\begin{array}{c}\rho \\
\left(\mathrm{kg} \cdot \mathrm{m}^{-3}\right)\end{array}$ & $\begin{array}{c}\pi \cdot 10^{-11} \\
\left(\mathrm{~kg} \cdot \mathrm{s}^{-1} \cdot \mathrm{m}^{-1} \cdot \mathrm{Pa}^{-1}\right)\end{array}$ & $\mu$ & $\begin{array}{c}\text { Sd } \\
\text { Wet cup }\end{array}$ \\
\hline Dry cup & $355(5)$ & $6.8(1.0)$ & $2.9(0.4)$ & $1.0(0.2)$ \\
\hline & $342(5)$ & $4.2(0.5)$ & $4.8(0.6)$ & $1.7(0.2)$ \\
\hline
\end{tabular}

The water vapour resistance factors for straw-clay were compared against results obtained with biobased and conventional self-insulating materials. Results for the dry cup test are presented in Fig. 6. Reference values were obtained in [55,59] for AAC, [59] for wood concrete, and [54,60,61] for the hemp concretes. For the wet cup test, results were available for reference $[55,59,60]$ only. They are presented in Fig. 7. 


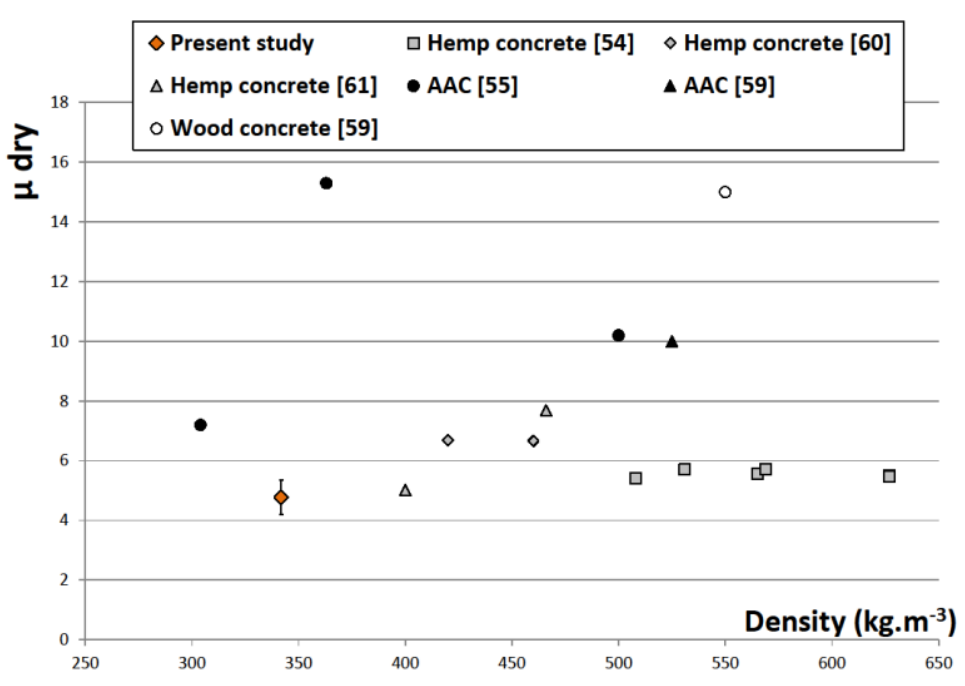

Fig. 6: Water vapour resistance factors of straw-clay and other building materials measured with dry cup method versus dry density

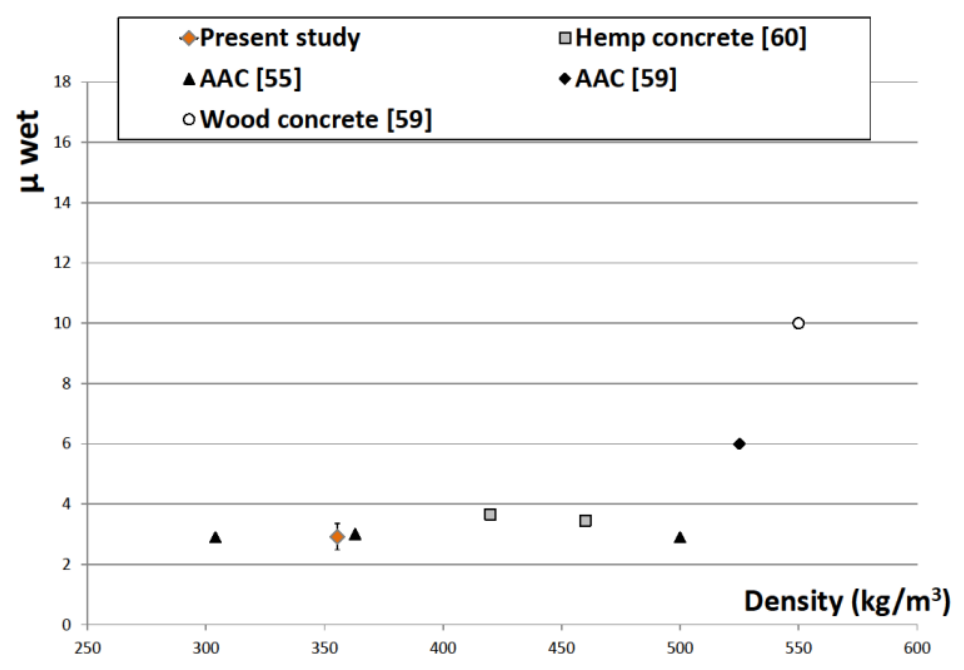

Fig. 7: Water vapour resistance factors of straw-clay and other building materials measured with wet cup method versus dry density

The water vapour resistance factors determined with wet cup are systematically higher than with dry cup. This can be explained by the additional liquid transfer due to capillary forces occurring for high moisture content. Straw-clay water vapour permeability equals or exceeds that of the other building materials in both wet and dry cups. This performance constitutes a good indicator for the use of strawclay as water vapour diffusion - open insulation systems for the rehabilitation of old buildings [62]. 


\section{Numerical assessment of the buffering potential}

\subsection{Numerical simulation of a small room}

The simulated case was very close to the one described in [28]. In this paper however, the wall can exchange heat and vapour with both the indoors and the outdoors, while in [28], only vapour transfer with the indoors was considered. The simulated case can be summarized as follows:

- A $90 \mathrm{~m}^{3}$ room was considered ;

- No distinction was made between the walls, so a single $60 \mathrm{~m}^{2}$ wall was simulated. The building structure was not modelled and there was no window and no door ;

- The ventilation rate remained constant and was equal to 0.5 Air Change per Hour (ach). This is a consensus value which corresponds to most European standards and construction habits [63];

- The indoor air was assumed to be perfectly mixed ;

- Indoor temperature was maintained at $20^{\circ} \mathrm{C}$;

- Steady outdoor conditions were assumed $\left(10^{\circ} \mathrm{C} ; \psi=65 \%\right)$. This is a strong simplification as the real outdoor conditions are constantly varying, which influences the moisture balance of indoor air. However, it would be harder to distinguish the influence of the materials from the outdoor conditions and limit the conclusions to specific climates. Therefore, some authors prefer to consider constant conditions, for both experimental and numerical studies [28,31,32]. For the same reason, the influence of sun, wind and rain was not taken into account ;

- Every 24 hours, a moisture generator was turned on for 8 hours. The moisture production rate was $300 \mathrm{~g} . \mathrm{h}^{-1}$. This value is high compared to those usually observed in dwellings. For example, the moisture production rate for light human activity is ranging from 30 to $60{\mathrm{~g} . \mathrm{h}^{-1}}^{\text {[64]. }}$. However, it allows obtaining the same magnitude of relative humidity variations than the one used in the MBV test [27].

HAM-Tools libraries were used to investigate the vapour transfer at room scale. It was based on Simulink / Matlab software [65] and was successfully validated through a numerical comparison with other models [66]. Heat and mass balances in porous materials (see Eq. 12 and Eq. 13) were solved by using the finite difference technique from a one-dimensional point of view. The following assumptions were used:

- There was no airflow crossing the wall and no air leakage;

- The moisture content remained low enough for it to be assumed that the super-hygroscopic state was never reached. Therefore, the vapour transfer was governed by vapour pressure only and liquid transport was not involved;

- No hysteresis was taken into account for the sorption property ;

- The enthalpy of the moisture content in the materials and the latent heat effect were included in the energy balance;

- The material properties related to moisture content were updated at each time step for all nodes; 
- The frame of the building was not modelled.

Eq. 12

$$
\begin{aligned}
-\frac{1}{V} \frac{\partial H}{\partial t} & =\operatorname{div}(-\lambda \overrightarrow{\operatorname{grad} T})+\operatorname{div}\left(g_{V} \cdot\left(L_{V}+C p_{V} \cdot T\right)\right) \\
H & =m_{M} \cdot C p_{M} \cdot T+w \cdot V \cdot\left(L_{V}+C p_{V} \cdot T\right) \\
-\frac{\partial w}{\partial t} & =\operatorname{div}\left(g_{V}\right) \\
& =\operatorname{div}\left(-\pi(w) \cdot \overrightarrow{\operatorname{grad}}\left(p_{V}\right)\right)
\end{aligned}
$$

Heat and mass balances for indoor air were also computed and the effects of heating and ventilation systems were included. The convective heat transfer coefficient was set to $6 \mathrm{~W} \cdot \mathrm{m}^{-2} \cdot \mathrm{K}^{-1}$ and the convective mass transfer coefficient was set to $2.10^{-8} \mathrm{~s}^{-\mathrm{m}^{-1}}$ (the same value was used in [28]). Finally, the moisture balance at the room scale results from the combination of the moisture sources $\left(\mathrm{g}_{\mathrm{v}, \text { source }}\right)$, the

air change rate $\left(\mathrm{g}_{\mathrm{v} \text {,Airchange }}\right)$, the moisture transfer with the walls $\left(\mathrm{g}_{\mathrm{v} \text {,Walls }}\right)$ and the variation of the moisture content of indoor air $\left(m_{V, A}\right)$. A positive value means that moisture is transferred to indoor air. It was computed as follows:

Eq. 14

$$
\frac{\partial m_{V, A}}{\partial t}=G_{V, \text { Wall }}+G_{V, \text { Source }}+G_{V, \text { AirChange }}
$$

The same scenario was applied to various wall configurations. The hygric response of a $350 \mathrm{~mm}$ thick wall made of straw-clay was compared to those of five walls made of hemp concrete (HC). A conventional wall assembly was defined by considering a wall made of $200 \mathrm{~mm}$ of concrete, $130 \mathrm{~mm}$ of polystyrene and a $13 \mathrm{~mm}$ thick plaster board as the indoor finishing. This wall configuration was selected as it its thermal resistance was very close to that of a $350 \mathrm{~mm}$ thick wall made of straw-clay. In order to investigate the influence of the indoor finishing, the simulations were repeated by adding $20 \mathrm{~mm}$ thick indoor finishing of different types (namely lime, earth and a mixture of hemp and lime). As this study focuses only on the impact of the wall assembly on indoor relative humidity, the influence of the outdoor finishing was assumed to be negligible and is not discussed in this paper. All the material properties were found in the literature and are given in section 7. The indoor finishing was meshed with 20 nodes of constant thickness while the rest of the wall was meshed with 60 nodes of constant thickness. Increasing the number of nodes did not have any significant influence on the results.

\subsection{Results and discussion}

\subsubsection{Influence of the wall assembly}

The main result from the simulation was the amplitude of the indoor relative humidity over a $24 \mathrm{~h}$ cycle. As mentioned in section 1.2, other indexes could have been computed. However, the main advantage of considering the amplitude of indoor variations is that it is very easy to analyse and is directly related to indoor comfort: lower amplitude can be analysed as an indication of an improvement in comfort. Finally, it was also selected in [28] to compare the impact of different indoor finishing. 
In order to avoid the influence of the initial conditions, the $24 \mathrm{~h}$ scenario was repeated as long as the amplitude variations exceeded $0.01 \%$ for two consecutive days. A first case was simulated by neglecting the vapour transfer with the wall (see Fig. 8): this corresponds to the case where a non-hygroscopic material is used.

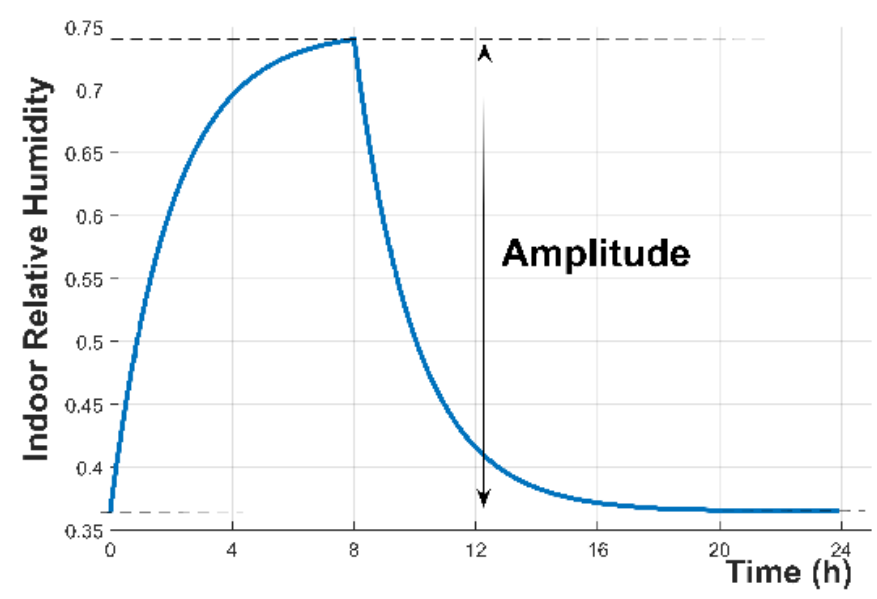

Fig. 8: Variation of indoor relative humidity when the wall is made of a non-hygroscopic material

The moisture production took place between 0 and $8 \mathrm{~h}$ and resulted in an increase in indoor relative humidity from $36.5 \%$ to $74 \%$. Because of the air change rate, the indoor relative humidity started to decrease as soon as the moisture generator was turned off. Then, indoor relative humidity reached $34 \%$ again, which corresponds to the humidity ratio $(r)$ of outdoor air heated to $20^{\circ} \mathrm{C}$. In this case, the amplitude was $37.5 \%$, which was very close to the value obtained in [28] (37\%). The results for all the different wall configurations are compared in Table 4.

Table 4 : Comparison of the indoor RH amplitude for the different simulated walls

\begin{tabular}{ccccc}
\hline \multirow{2}{*}{ Main material } & \multicolumn{4}{c}{ RH amplitude } \\
\cline { 2 - 5 } & $\begin{array}{c}\text { no } \\
\text { finishing }\end{array}$ & Lime & Earth & Lime + Hemp \\
\hline Concrete + polystyrene + plaster & $22.6 \%$ & $12.4 \%$ & $9.5 \%$ & $13.6 \%$ \\
Straw-clay mixture & $13.7 \%$ & $12.3 \%$ & $9.5 \%$ & $13.8 \%$ \\
HC 1 & $14.3 \%$ & $12.2 \%$ & $9.4 \%$ & $13.6 \%$ \\
HC 2 & $10.1 \%$ & $12.3 \%$ & $9.5 \%$ & $13.8 \%$ \\
HC 3 & $9.9 \%$ & $12.3 \%$ & $9.4 \%$ & $13.8 \%$ \\
HC 4 & $13.8 \%$ & $12.3 \%$ & $9.4 \%$ & $13.7 \%$ \\
HC 5 & $11.4 \%$ & $12.4 \%$ & $9.6 \%$ & $13.9 \%$ \\
\hline
\end{tabular}

First, it should be observed that all wall configurations had an impact on the amplitude of indoor relative humidity, even when the conventional case was considered (22.6\%). However, the amplitude was far lower with straw-clay (13.7\%) or hemp concrete (from 9.9 to $14.3 \%$ ). This indicates that straw-clay and hemp concrete moderate indoor relative humidity in a similar way. This result was not straightforward as some sizeable differences were observed for both the vapour permeability (up to a factor 5 ) and the 
sorption isotherm (up to a factor 2). Still, the lowest amplitudes were obtained with HC2 and HC3, for which the highest vapour permeability and sorption values were obtained.

Second, the moisture buffering effect proved to be strongly influenced by the indoor finishing. The results were within a narrow range $( \pm 0.3 \%)$ for all the wall assemblies as soon as the same finishing was applied. This statement even applies to the conventional wall assembly, meaning that, in the specific configuration of this simulated case, the hygric buffering of the wall assembly was totally governed by the hygric performance of the indoor coating. Earth was found to be the most effective coating (the average amplitude was $9.6 \%)$, followed by lime (12.4\%) and the mixture of lime and hemp (13.8\%).

This little computational exercise demonstrates that a straw-clay mixture should be as efficient as hemp concrete to lower indoor relative humidity variations. However, this positive assessment is somewhat mitigated by the strong influence of the indoor finishing: there was no clear difference between a wall made of concrete and a wall made of straw-clay or hemp concrete as soon as a $20 \mathrm{~mm}$ thick coating was applied.

\subsubsection{Influence of the thickness of the coating}

In order to better assess the influence of the coatings, additional simulations were run, in which the thickness of the coating varied from 2 to $20 \mathrm{~mm}$ by steps of $2 \mathrm{~mm}$. For the sake of clarity, only three different wall assemblies were considered: the conventional wall assembly, a wall made of straw-clay and a wall made of hemp concrete (HC3). The results are presented in Fig. 9 for lime, Fig. 10 for earth, and Fig. 11 for a mixture of lime and hemp.

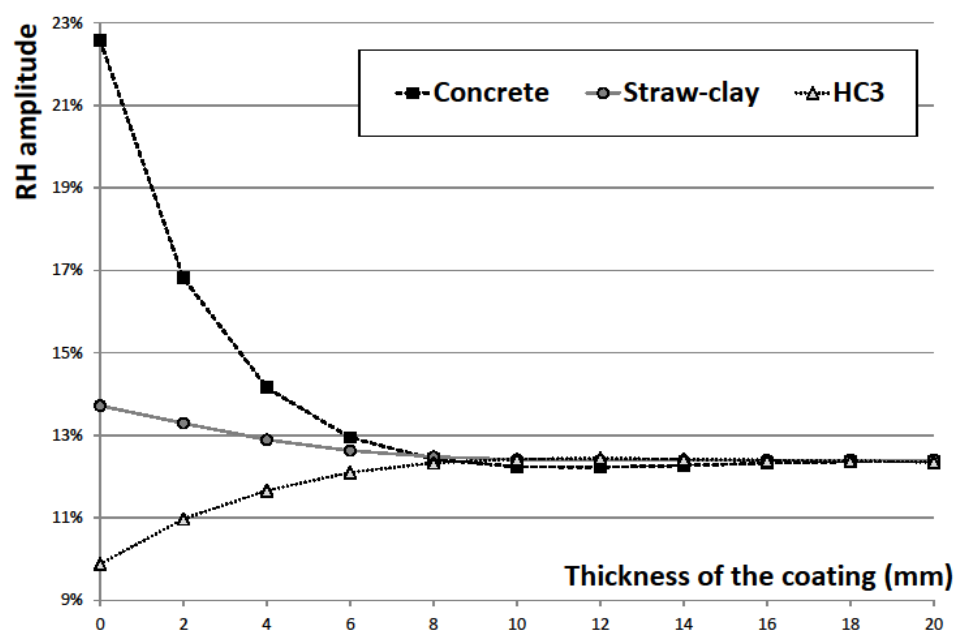

Fig. 9: Impact of the thickness of a coating made of lime on the RH amplitude 


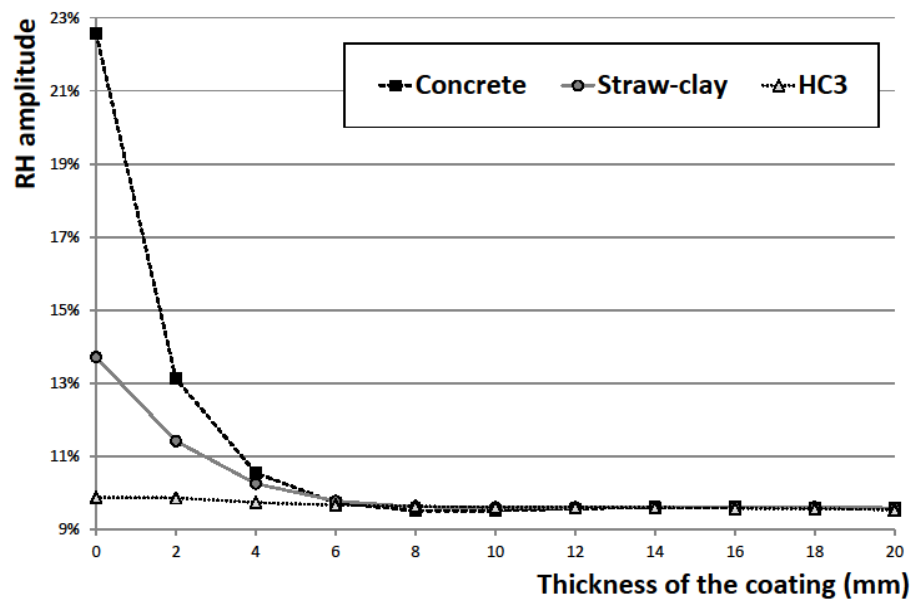

Fig. 10: Impact of the thickness of a coating made of earth on the RH amplitude

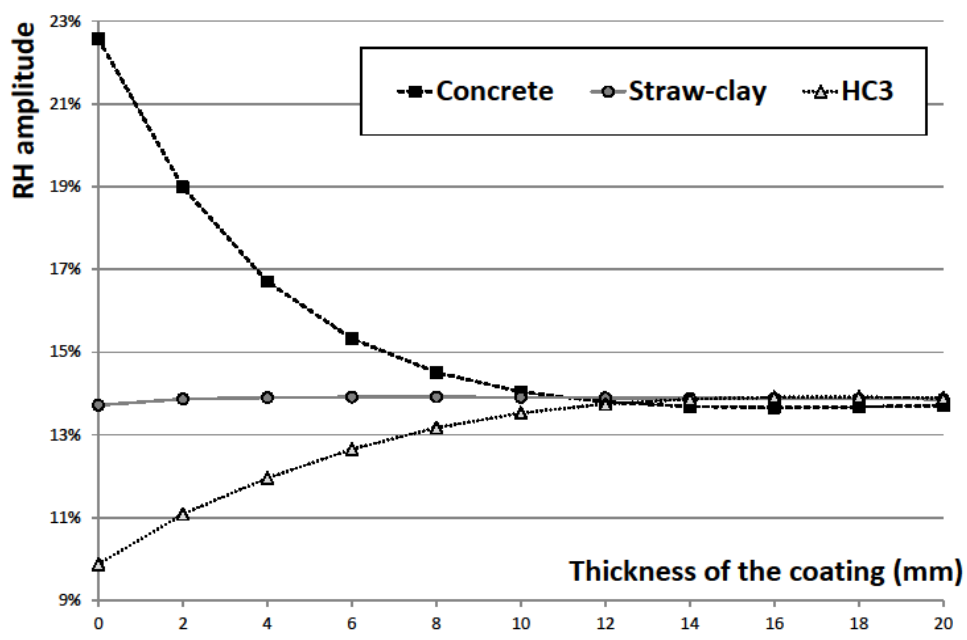

Fig. 11: Impact of the thickness of a coating made of lime and hemp on the RH amplitude

It emerged that the coating was influential even for small thicknesses. The difference in the amplitude of indoor relative humidity between the three wall assemblies remained lower than $1 \%$ as soon as the coating was thicker than $10 \mathrm{~mm}$. It was even lower for the specific case of earth (only $4 \mathrm{~mm}$ ). It should be underlined that the lowest RH amplitude was also obtained with earth. Therefore, it could be concluded that indoor RH amplitude could be efficiently managed by a thin layer of earth.

Increasing the thickness of the coating above $10 \mathrm{~mm}$ had no noticeable influence on the indoor relative humidity amplitude. This is reminiscent of the theoretical concept of penetration depth, which was used in the development of the MBV test in particular. One advantage of the numerical approach presented here is to allow the $\mathrm{RH}$ amplitude to be determined when the thickness of the coating is less than the penetration depth and for any type of indoor moisture variation.

Finally, it should be underlined that this numerical work focuses on short term issues only. Long term concerns should be also addressed to give a more comprehensive comparison of the different wall assemblies. Mould growth is of particular relevance, because of the presumed high sensitivity of straw. 
Further work could be inspired by the methodology initiated in [67], or uses one of the technique reviewed in [68]. To prevent from mould growth, chemical add-on may be considered. However, its use is likely to decrease the vapour permeability so as the buffering potential: this was observed in [39] where four different acrylic and vinyl finishing were applied on gypsum boards. Consequently, the rather good performances obtained here may be lowered, yet the same may be true for the other wall assemblies.

\section{Conclusion}

In this paper, the basic hygrothermal properties of straw-clay samples provided by two French companies were determined in laboratory conditions. Repeatable density was measured on the samples, which revealed a good mastery of the fabrication process by the manufacturers and gave confidence in the characterization of the mixtures. By modifying the clay to straw ratio, densities ranging from approximately 250 to $550 \mathrm{~kg} \cdot \mathrm{m}^{-3}$ could be obtained.

The dry thermal conductivities of straw-clay mixtures (ranging from 0.071 to $0.120 \mathrm{~W} . \mathrm{m}^{-1} \cdot \mathrm{K}^{-1}$ ) were comparable with those of hemp concretes or aerated autoclaved concrete (AAC) of equivalent density. A high sorption capacity was also measured, as well as very high water vapour permeability. These results suggested that straw-clay could be advantageously used in buildings for its ability to lower heat transfer, but also to moderate indoor humidity variations.

To strengthen this statement, a numerical model able to handle coupled heat and vapour transfer in wall assemblies was used to simulate the hygric response of a small room. The moisture buffering effect of the straw-clay mixture was found to be of the same magnitude as in walls made of hemp concrete and largely higher than conventional wall. As neither material is ever exposed directly to the indoor conditions, further simulations were carried by adding some indoor finishing currently used in combination with bio-based materials. There was no clear difference between a wall made of concrete and a wall made of straw-clay or hemp concrete as soon as a 10-mm-thick coating was applied. Consequently, the rather good moisture buffering of straw-clay may be overshadowed by the hygroscopic properties of the finishing. The influence of the finishing on the overall performance of the wall seems sizeable and should be studied more in details, by considering long-term concerns for example.

On the other hand, straw-clay is mostly used as an in-fill material, meaning it is a component of a multilayer wall. In wooden-frame structures, the wall may include one or several of the followings: a vapour barrier, a ventilated air cavity, a protection against wind-driven rain and braced wall panels. All of these elements have different hygrothermal properties, so that the behaviour of the whole assembly cannot be simply assessed. Some examples can be found in [40] for classical assemblies in a wooden frame-house. Numerical simulations at wall and building scales combined with an experimental campaign at wall scale could help to explore these aspects for straw-clay. 
Finally, the impacts of clay mineralogy, straw nature and processing, or straw to clay proportions on the hygrothermal performance of straw-clay have to be investigated. This would allow the design of such composites to be optimized.

\section{Acknowledgements}

The authors would like to thank Ecoterre and Inventerre for their support in this project.

\section{References}

[1] Ministère du développement durable et de l'énergie, L'environnement en France, (2014). http://www.statistiques.developpementdurable.gouv.fr/fileadmin/documents/Produits_editoriaux/Publications/References/2014/referenc es-ree-2014.pdf.

[2] G. Minke, Building with Earth: Design and Technology of a Sustainable Architecture, Birkhäuser Architecture, 2009.

[3] F. Pacheco-Torgal, S. Jalali, Earth construction: Lessons from the past for future eco-efficient construction, Constr. Build. Mater. 29 (2012) 512-519. doi:10.1016/j.conbuildmat.2011.10.054.

[4] H. Danso, B. Martinson, M. Ali, C. Mant, Performance characteristics of enhanced soil blocks: a quantitative review, Build. Res. Inf. 43 (2015) 253-262. doi:10.1080/09613218.2014.933293.

[5] D. Samri, Analyse physique et caractérisation hygrothermique des matériaux de construction: approche expérimentale et modélisation numérique, Ecole Nationale des Travaux Publics de l'Etat, 2008. http://theses.insa-lyon.fr/publication/2008ISAL0067/these.pdf (accessed September 3, 2014).

[6] Y.A. Oumeziane, Evaluation des performances hygrothermiques d'une paroi par simulation numérique: application aux parois en béton de chanvre, INSA de Rennes, 2013. https://hal.archives-ouvertes.fr/tel-00871004/ (accessed July 23, 2015).

[7] F. McGregor, A. Heath, A. Shea, M. Lawrence, The moisture buffering capacity of unfired clay masonry, Build. Environ. 82 (2014) 599-607. doi:10.1016/j.buildenv.2014.09.027.

[8] H. Cagnon, J.E. Aubert, M. Coutand, C. Magniont, Hygrothermal properties of earth bricks, Energy Build. 80 (2014) 208-217. doi:10.1016/j.enbuild.2014.05.024.

[9] P. Maillard, J.E. Aubert, Effects of the anisotropy of extruded earth bricks on their hygrothermal properties, Constr. Build. Mater. 63 (2014) 56-61. doi:10.1016/j.conbuildmat.2014.04.001.

[10] S. Liuzzi, M.R. Hall, P. Stefanizzi, S.P. Casey, Hygrothermal behaviour and relative humidity buffering of unfired and hydrated lime-stabilised clay composites in a Mediterranean climate, Build. Environ. 61 (2013) 82-92. doi:10.1016/j.buildenv.2012.12.006.

[11] D. Allinson, M. Hall, Hygrothermal analysis of a stabilised rammed earth test building in the UK, Energy Build. 42 (2010) 845-852. doi:10.1016/j.enbuild.2009.12.005.

[12] S. Goodhew, R. Griffiths, Sustainable earth walls to meet the building regulations, Energy Build. 37 (2005) 451-459. doi:10.1016/j.enbuild.2004.08.005.

[13] A. Bouguerra, A. Ledhem, F. De Barquin, R.M. Dheilly, M. Queneudec, Effect of microstructure on the mechanical and thermal properties of lightweight concrete prepared from clay, cement, and wood aggregates, Cem. Concr. Res. 28 (1998) 1179-1190. 
[14] K. Al Rim, A. Ledhem, O. Douzane, R.M. Dheilly, M. Queneudec, Influence of the proportion of wood on the thermal and mechanical performances of clay-cement-wood composites, Cem. Concr. Compos. 21 (1999) 269-276.

[15] A. Ledhem, R.M. Dheilly, M.L. Benmalek, M. Quéneudec, Properties of wood-based composites formulated with aggregate industry waste, Constr. Build. Mater. 14 (2000) 341-350.

[16] T. Ashour, H. Wieland, H. Georg, F.-J. Bockisch, W. Wu, The influence of natural reinforcement fibres on insulation values of earth plaster for straw bale buildings, Mater. Des. 31 (2010) 46764685. doi:10.1016/j.matdes.2010.05.026.

[17] T. Ashour, H. Georg, W. Wu, An experimental investigation on equilibrium moisture content of earth plaster with natural reinforcement fibres for straw bale buildings, Appl. Therm. Eng. 31 (2011) 293-303. doi:10.1016/j.applthermaleng.2010.09.009.

[18] J. Pinto, A. Paiva, H. Varum, A. Costa, D. Cruz, S. Pereira, et al., Corn's cob as a potential ecological thermal insulation material, Energy Build. 43 (2011) 1985-1990. doi:10.1016/j.enbuild.2011.04.004.

[19] P. Faria, T. Santos, J.E. Aubert, Characterization of an earth plaster - A contribution to the increased use of these eco-efficient plasters, J Mater Civ Eng. (submitted).

[20] Y. Millogo, J.-C. Morel, J.-E. Aubert, K. Ghavami, Experimental analysis of Pressed Adobe Blocks reinforced with Hibiscus cannabinus fibers, Constr. Build. Mater. 52 (2014) 71-78. doi:10.1016/j.conbuildmat.2013.10.094.

[21] Y. Millogo, J.-E. Aubert, E. Hamard, J.-C. Morel, How Properties of Kenaf Fibers from Burkina Faso Contribute to the Reinforcement of Earth Blocks, Materials. 8 (2015) 2332-2345. doi:10.3390/ma8052332.

[22] J. Khedari, P. Watsanasathaporn, J. Hirunlabh, Development of fibre-based soil-cement block with low thermal conductivity, Cem. Concr. Compos. 27 (2005) 111-116. doi:10.1016/j.cemconcomp.2004.02.042.

[23] H. Bal, Y. Jannot, S. Gaye, F. Demeurie, Measurement and modelisation of the thermal conductivity of a wet composite porous medium: Laterite based bricks with millet waste additive, Constr. Build. Mater. 41 (2013) 586-593. doi:10.1016/j.conbuildmat.2012.12.032.

[24] P. Meukam, A. Noumowe, Y. Jannot, R. Duval, Caractérisation thermophysique et mécanique de briques de terre stabilisées en vue de l'isolation thermique de bâtiment, Mater. Struct. 36 (2003) 453-460.

[25] M. Maddison, T. Mauring, K. Kirsimäe, Ü. Mander, The humidity buffer capacity of clay-sand plaster filled with phytomass from treatment wetlands, Build. Environ. 44 (2009) 1864-1868. doi:10.1016/j.buildenv.2008.12.008.

[26] V. Cérézo, Propriétés mécaniques, thermiques et acoustiques d'un matériau à base de particules végétales: approche expérimentale et modélisation théorique, Ecole Nationale des Travaux Publics de l'Etat, 2005. http://theses.insa-lyon.fr/publication/2005isal0037/these.pdf (accessed April 14, 2015).

[27] C. Rode, R.H. Peuhkuri, L.H. Mortensen, K.K. Hansen, B. Time, A. Gustavsen, et al., Moisture buffering of building materials, Technical University of Denmark, Department of Civil Engineering, 2005. http://orbit.dtu.dk/fedora/objects/orbit:75984/datastreams/file_2415500/content (accessed April 15, 2015).

[28] S. Roels, H. Janssen, A Comparison of the Nordtest and Japanese Test Methods for the Moisture Buffering Performance of Building Materials, J. Build. Phys. 30 (2006) 137-161. doi:10.1177/1744259106068101.

[29] F. McGregor, A. Heath, E. Fodde, A. Shea, Conditions affecting the moisture buffering measurement performed on compressed earth blocks, Build. Environ. 75 (2014) 11-18. doi:10.1016/j.buildenv.2014.01.009. 
[30] S. Hameury, Moisture buffering capacity of heavy timber structures directly exposed to an indoor climate: a numerical study, Build. Environ. 40 (2005) 1400-1412. doi:10.1016/j.buildenv.2004.10.017.

[31] X. Yang, P. Fazio, H. Ge, J. Rao, Evaluation of moisture buffering capacity of interior surface materials and furniture in a full-scale experimental investigation, Build. Environ. 47 (2012) 188196. doi:10.1016/j.buildenv.2011.07.025.

[32] H. Zhang, H. Yoshino, K. Hasegawa, Assessing the moisture buffering performance of hygroscopic material by using experimental method, Build. Environ. 48 (2012) 27-34. doi:10.1016/j.buildenv.2011.08.012.

[33] M. Woloszyn, T. Kalamees, M. Olivier Abadie, M. Steeman, A. Sasic Kalagasidis, The effect of combining a relative-humidity-sensitive ventilation system with the moisture-buffering capacity of materials on indoor climate and energy efficiency of buildings, Build. Environ. 44 (2009) 515-524. doi:10.1016/j.buildenv.2008.04.017.

[34] Y. Li, P. Fazio, J. Rao, An investigation of moisture buffering performance of wood paneling at room level and its buffering effect on a test room, Build. Environ. 47 (2012) 205-216. doi:10.1016/j.buildenv.2011.07.021.

[35] H. Janssen, S. Roels, Qualitative and quantitative assessment of interior moisture buffering by enclosures, Energy Build. 41 (2009) 382-394. doi:10.1016/j.enbuild.2008.11.007.

[36] X. Lu, Estimation of indoor moisture generation rate from measurement in buildings, Build. Environ. 38 (2003) 665-675. doi:10.1016/S0360-1323(02)00237-8.

[37] T. Kalamees, Indoor Humidity Loads and Moisture Production in Lightweight Timber-frame Detached Houses, J. Build. Phys. 29 (2006) 219-246. doi:10.1177/1744259106060439.

[38] M. Rahim, O. Douzane, A.D. Tran Le, G. Promis, B. Laidoudi, A. Crigny, et al., Characterization of flax lime and hemp lime concretes: Hygric properties and moisture buffer capacity, Energy Build. 88 (2015) 91-99. doi:10.1016/j.enbuild.2014.11.043.

[39] N.M.M. Ramos, J.M.P.Q. Delgado, V.P. de Freitas, Influence of finishing coatings on hygroscopic moisture buffering in building elements, Constr. Build. Mater. 24 (2010) 2590-2597. doi:10.1016/j.conbuildmat.2010.05.017.

[40] M. Labat, M. Woloszyn, G. Garnier, J.J. Roux, Dynamic coupling between vapour and heat transfer in wall assemblies: Analysis of measurements achieved under real climate, Build. Environ. 87 (2015) 129-141. doi:10.1016/j.buildenv.2015.01.022.

[41] J. Carmeliet, D. Derome, Temperature driven inward vapor diffusion under constant and cyclic loading in small-scale wall assemblies: Part 2 heat-moisture transport simulations, Build. Environ. 47 (2012) 161-169. doi:10.1016/j.buildenv.2011.07.028.

[42] A. Piot, M. Woloszyn, J. Brau, C. Abele, Experimental wooden frame house for the validation of whole building heat and moisture transfer numerical models, Energy Build. 43 (2011) 1322-1328. doi:10.1016/j.enbuild.2011.01.008.

[43] Y. Mualem, A conceptual model of hysteresis, Water Resour. Res. 10 (1974) 514-520.

[44] J. Carmeliet, M. De Wit, H. Janssen, Hysteresis and moisture buffering of wood, in: Symp. Build. Phys. Nord. Ctries., 2005: pp. 55-62. http://web.byv.kth.se/bphys/reykjavik/pdf/art_032.pdf (accessed October 4, 2013).

[45] J. Kwiatkowski, M. Woloszyn, J.-J. Roux, Modelling of hysteresis influence on mass transfer in building materials, Build. Environ. 44 (2009) 633-642. doi:10.1016/j.buildenv.2008.05.006.

[46] Y. Aït Oumeziane, M. Bart, S. Moissette, C. Lanos, Hysteretic Behaviour and Moisture Buffering of Hemp Concrete, Transp. Porous Media. 103 (2014) 515-533. doi:10.1007/s11242-014-0314-7.

[47] O.F. Osanyintola, C.J. Simonson, Moisture buffering capacity of hygroscopic building materials: Experimental facilities and energy impact, Energy Build. 38 (2006) 1270-1282. 
[48] T.Z. Desta, J. Langmans, S. Roels, Experimental data set for validation of heat, air and moisture transport models of building envelopes, Build. Environ. 46 (2011) 1038-1046. doi:10.1016/j.buildenv.2010.11.002.

[49] NF EN ISO 12664 Thermal performance of building materials and products - Determination of thermal resistance by means of guarded hot plate and heat flow meter methods - Dry and moist products of medium and low thermal resistance, (2001).

[50] T.M. Dinh, Contribution to the development of precast hempcrete using innovative pozzolanic binder, Université de Toulouse, 2014.

[51] NF EN ISO 12570 Hygrothermal performance of building materials and products - Measurement of the moisture content by the hot air heating method, (2000).

[52] NF EN ISO 12571 Hygrothermal performance of building materials and products - Determination of hygroscopic sorption properties, (2013).

[53] NF EN ISO 12572 Hygrothermal performance of building materials and products - Determination of water vapour transmission properties, (2001).

[54] R. Walker, S. Pavía, Moisture transfer and thermal properties of hemp-lime concretes, Constr. Build. Mater. 64 (2014) 270-276. doi:10.1016/j.conbuildmat.2014.04.081.

[55] M. Jerman, M. Keppert, J. Výborný, R. Černý, Hygric, thermal and durability properties of autoclaved aerated concrete, Constr. Build. Mater. 41 (2013) 352-359. doi:10.1016/j.conbuildmat.2012.12.036.

[56] J.J. del Coz Díaz, F.P. Álvarez Rabanal, P.J. García Nieto, J. Domínguez Hernández, B. Rodríguez Soria, J.M. Pérez-Bella, Hygrothermal properties of lightweight concrete: Experiments and numerical fitting study, Constr. Build. Mater. 40 (2013) 543-555. doi:10.1016/j.conbuildmat.2012.11.045.

[57] F. Collet, J. Chamoin, S. Pretot, C. Lanos, Comparison of the hygric behaviour of three hemp concretes, Energy Build. 62 (2013) 294-303. doi:10.1016/j.enbuild.2013.03.010.

[58] S. Roels, P. Talukdar, C. James, C.J. Simonson, Reliability of material data measurements for hygroscopic buffering, Int. J. Heat Mass Transf. 53 (2010) 5355-5363. doi:10.1016/j.ijheatmasstransfer.2010.07.020.

[59] CSTB, Th-U. Règles, (2012).

[60] J. Chamoin, Optimisation des propriétés (physiques, mécaniques et hydriques) de bétons de chanvre par la maîtrise de la formulation, INSA de Rennes, 2013. https://tel.archivesouvertes.fr/tel-00934732/ (accessed July 23, 2015).

[61] A. Evrard, Sorption behaviour of Lime-Hemp Concrete and its relation to indoor comfort and energy demand, in: Proc. 23rd Conf. Passive Low Energy Archit. Geneva Switz., 2006. http://www.researchgate.net/profile/Arnaud_Evrard/publication/242214213_Sorption_behaviour _of_Lime-

Hemp_Concrete_and_its_relation_to_indoor_comfort_and_energy_demand/links/53df4fef0cf 216 e4210c760d.pdf (accessed July 23, 2015).

[62] G. Scheffler, Hygric performance of internal insulation with light-weight autoclaved aerated concrete, in: Bydgoszcz, Poland, 2011.

[63] J. Laverge, X. Pattyn, A. Janssens, Performance assessment of residential mechanical exhaust ventilation systems dimensioned in accordance with Belgian, British, Dutch, French and ASHRAE standards, Build. Environ. 59 (2013) 177-186. doi:10.1016/j.buildenv.2012.08.018.

[64] IEA Annex XIV, Condensation and Energy - Sourcebook, 1991.

[65] A.S. Kalagasidis, P. Weitzmann, T.R. Nielsen, R. Peuhkuri, C.-E. Hagentoft, C. Rode, The International Building Physics Toolbox in Simulink, Energy Build. 39 (2007) 665-674. doi:10.1016/j.enbuild.2006.10.007. 
[66] M. Woloszyn, C. Rode, Tools for performance simulation of heat, air and moisture conditions of whole buildings, Build. Simul. 1 (2008) 5-24.

[67] A. Simons, A. Laborel-Préneron, A. Bertron, J.E. Aubert, C. Magniont, C. Roux, et al., Development of bio-based earth products for healthy and sustainable buildings: characterization of microbiological, mechanical and hygrothermal properties, Matér. Tech. 103 (2015) 206. doi:10.1051/mattech/2015011.

[68] E. Vereecken, S. Roels, Review of mould prediction models and their influence on mould risk evaluation, Build. Environ. 51 (2012) 296-310. doi:10.1016/j.buildenv.2011.11.003.

[69] T.L. Vu, S. Spagnol, C. Magniont, Experimental study of the hygrothermal behaviour of hemp shives based precast blocks at material and wall scales, (2015). http://www.irit.fr/neocampus/uploads/Projects/Publis/ICBBM_Vu_Spagnol_Magniont.pdf (accessed July 23, 2015).

[70] I.Y. Gnip, S.A. Veyalis, V.I. Kershulis, Isotherms of water vapor sorption by light inorganic and polymer heat-insulating materials, J. Eng. Phys. Thermophys. 79 (2006) 40-47.

\section{Appendix}

Table 5 : Material properties extracted from the literature and used for modelling purposes

\begin{tabular}{|c|c|c|c|c|c|}
\hline Material & $\begin{array}{c}\rho \\
\mathrm{kg} \cdot \mathrm{m}^{-3}\end{array}$ & $\begin{array}{c}\lambda \\
\mathrm{W} \cdot \mathrm{m}^{-1} \cdot \mathrm{K}^{-1}\end{array}$ & $\begin{array}{c}\mathrm{Cp} \\
\mathrm{kJ} \cdot \mathrm{kg}^{-1} \cdot \mathrm{K}^{-1}\end{array}$ & $\begin{array}{c}\pi \cdot 10^{-11} \\
\mathrm{~kg} \cdot \mathrm{s}^{-1} \cdot \mathrm{m}^{-1} \cdot \mathrm{Pa}^{-1} \\
\text { dry cup }\end{array}$ & $\begin{array}{l}\pi \cdot 10^{-11} \\
\mathrm{~kg} \cdot \mathrm{s}^{-1} \cdot \mathrm{m}^{-1} \cdot \mathrm{Pa}^{-1} \\
\text { wet cup }\end{array}$ \\
\hline Concrete [59] & 2450 & 2.00 & $1000^{(1)}$ & 0.15 & 0.24 \\
\hline Plaster [59] & 875 & 0.25 & $1000^{(1)}$ & 1.90 & 4.75 \\
\hline Polystyrene [59] & 50 & 0.04 & 1450 & \multicolumn{2}{|c|}{$0.32^{(2)}$} \\
\hline $\mathrm{HC} 1$ [5] & 430 & 0.11 & $1000^{(1)}$ & 1.70 & 2.30 \\
\hline $\mathrm{HC} 2$ [5] & 317 & 0.08 & $1000^{(1)}$ & \multicolumn{2}{|c|}{$5.30^{(2)}$} \\
\hline HC3 [69] & 453 & 0.10 & 912 & \multicolumn{2}{|c|}{$6.68^{(2)}$} \\
\hline $\mathrm{HC} 4[6]$ & 450 & 0.12 & 1250 & \multicolumn{2}{|c|}{$5.00^{(2)}$} \\
\hline $\mathrm{HC} 5[6]$ & 320 & 0.09 & 1250 & \multicolumn{2}{|c|}{$10.00^{(2)}$} \\
\hline Lime [60] & 1031 & 0.55 & $1000^{(1)}$ & 2.60 & 5.00 \\
\hline Earth[8] & 2060 & 0.59 & 990 & 2.50 & 6.20 \\
\hline Lime + Hemp [60] & 761 & 0.20 & $1000^{(1)}$ & 2.80 & 6.50 \\
\hline $\begin{array}{l}\text { Assumption - no v } \\
\text { A single value was }\end{array}$ & $\begin{array}{l}\text { vailable } \\
\text { for vap }\end{array}$ & neabil & & & \\
\hline
\end{tabular}

Models for sorption isotherms:

$\mathrm{HC}[5]$ :

$$
u=\frac{56.5 \cdot \psi}{-5.574 \cdot \psi^{2}+4.912 \cdot \psi+1}
$$

HC 2 [5]:

$$
u=\frac{38.4 \cdot \psi}{-2.221 \cdot \psi^{2}+1.3468 \cdot \psi+1}
$$


HC 3 [69]:

$$
u=\frac{0.1072 \cdot \psi \cdot(1-0.5596) \cdot(1+(1.2490-1) \cdot 0.5596)}{(1-0.5596 \cdot \psi) \cdot(1+(1.2490-1)) \cdot 0.5596 \cdot \psi}
$$

HC $4[6]$ :

$$
u=1.5 \cdot\left(1+\mid \frac{0.0119 \cdot R \cdot T}{\left.\left.M_{l} \cdot g \cdot \ln (\psi)\right|^{2.0462}\right)^{-1+\frac{1}{2.0462}}}\right.
$$

HC 5 [6]:

$$
u=2.4 \cdot\left(1+\left.\left|\frac{0.0747 \cdot R \cdot T}{M_{l} \cdot g \cdot} \cdot \ln (\psi)\right|\right|^{1.6921}\right)^{-1+\frac{1}{1.6921}}
$$

Plaster [58]:

$$
u=0.077 \cdot\left(1+|-215.23 \cdot \ln (\psi)|^{1.628}\right)^{-1+\frac{1}{1.628}}
$$

Lime [60]:

$$
u=\frac{0.010 \cdot 17.23 \cdot 0.904 \cdot \psi}{(1-0.904 \cdot \psi) \cdot(1+17.23 \cdot 0.904 \cdot \psi-0.904 \cdot \psi)}
$$

$$
\text { Lime + Hemp [60]: } \quad u=\frac{0.006 \cdot 3.546 \cdot 0.957 \cdot \psi}{(1-0.957 \cdot \psi) \cdot(1+3.546 \cdot 0.957 \cdot \psi-0.957 \cdot \psi)}
$$

Table 6 : Sorption values extracted from the literature and used for modelling purposes

\begin{tabular}{cccccccc}
\hline \multirow{2}{*}{ Concrete [59] } & $\Psi(\%)$ & 20 & 40 & 60 & 80 & 95 & \\
& $\mathrm{u}(\%)$ & 3.5 & 4.5 & 6.5 & 11 & 18 & \\
\hline \multirow{2}{*}{ Earth [8] } & $\psi(\%)$ & 7 & 33 & 50 & 76 & 97 & \\
& $\mathrm{u}(\%)$ & 0 & 1.22 & 1.76 & 2.77 & 8.74 & \\
\hline \multirow{2}{*}{ Polystyrene [70] } & $\psi(\%)$ & 20 & 40 & 60 & 80 & 90 & 97 \\
& $\mathrm{u}(\%)$ & 0.08 & 0.16 & 0.25 & 0.34 & 0.4 & 0.53 \\
\hline
\end{tabular}

